\title{
Branding In Insurance Sector: Brand Recall of Insurance Companies amongst the College Students of Delhi and Mumbai
}

\author{
Anuj Pal Kapoor ${ }^{1}$, Prof. Madhu Vij ${ }^{2}$ \\ ${ }^{1}$ Faculty of Management Studies, University of Delhi, Delhi \\ ${ }^{2}$ Faculty of Management Studies, University of Delhi, Delhi
}

\begin{abstract}
The study highlights the awareness level and brand recall of life insurance companies among the college students of Delhi and Mumbai. The intent of the study is to understand the outlook of college students, and the brand recall of insurance companies among the young generation of India. The college students are the potential customers for insurance companies and their outlook towards insurance is very critical for the insurance players. The study uses a survey approach methodology of around 810 college students from Delhi and Mumbai to gauge their understanding level and brand preference for life insurance companies in India. Data from the study confirms that $1 \%$ of the respondents have life insurance policies and around $2.5 \%$ of the respondents are aware about insurance as a concept. Amongst the life insurance companies, LIC, HDFC Life, ICICI Prudential and Max Life are the top companies with the highest brand recall whereas LIC and ICICI Prudential are the companies with whom, the students are most likely to get insured with. Factors such as age, gender and education are significant determinants of overall awareness levels and brand recall. In addition, geographic location also had a significant impact on the awareness and brand recall towards insurance companies. College students in Mumbai are more aware and have a positive outlook towards insurance as compared to Delhi. It can be concluded that the awareness pertaining to insurance in India is low and even lower among the college students. Secondly, even though every insurance company has a branding strategy in place but the brand recall for insurance companies varies from individual to individual. Brand recall for insurance companies in college student are influenced by marketing and advertising efforts and parents preference towards a particular brand.
\end{abstract}

Key words: Branding, Brand Recall, Brand Awareness, Life Insurance

\section{Introduction}

India's insurance industry has come a long way since the reforms of the 1990's. As of Sep 2015, 52 insurance companies were operating in the country, including 24 in life and 28 in non-life segments. Though the number of insurance companies operating in India has increased significantly, millions of people have limited awareness and/or access to insurance and financial services. India as a country still remains grossly 'underinsured' in terms of insurance penetration and density. In 2000-2005, the Insurance penetration - the ratio of premium volume to GDP was at 2.8 while it reached 3.3 in 2014-2015. The growth has been considerably sluggish and irregular, due to many factors such as product design, distribution, customer service, government \& regulatory issues with a considerable factor being limited financial awareness and literacy among the masses.

The youth in India are the future consumers. The awareness levels among the youth, specifically college students is abysmally low, which is a state of concern. Life insurance is a push based product and selling such as product becomes even more difficult, when the awareness level of the prospective buyer is lower. It is very essential that the youth sees a value in life insurance which can only be realised, when there is awareness. Therefore, it is of paramount importance for the companies to work towards creating awareness pertaining to life insurance amongst the youth in India.

When LIC started with its operations, it created its mark over a period of time, and gradually evolved from a mere Insurer provider to a brand with a promise "Zindagi ke saath bhi, Zindagi ke baad bhi". Today, LIC is the market leader in life insurance with a 70\% market share. With the limited resources LIC had decades ago, it created a brand name for itself which is still prevailing in the market. It is essential that the insurance companies create that mark in terms of their brand in the mind of the consumers. In such cases, branding is of economic importance to companies. With the advent of internet and relaxed regulation, the dynamics of life insurance industry has also changed. A lot of new players have entered into the Indian market and aggressively targeting the potential customers. Every life insurance company has a dedicated marketing team which focuses on the marketing strategies including branding. Companies are spending a good portion of their marketing budget on branding through designated brand managers.

Branding at a corporate level is essential to not only manage the relationship with the stakeholders but to have a connect with the masses as well. Branding in the insurance space is not limited to the company name but many other factors which contribute to the brand image such as company logo, customer service, partnering 
brands in terms of joint venture/association, brand ambassadors and advertising etc. One of the aim of branding is to make a brand unique to consumers. With the branding strategies adopted by insurance companies in India, they have been successful to a certain extent to differentiate themselves from other brands. In this paper, we examine the impact of branding of life insurance companies among the college students of Delhi and Mumbai along with the attitude of the consumers towards life insurance. Also, brand recall and preference of the college students for the life insurance companies in India has been studied and evaluated.

\section{Review of Literature}

The review of literature mentioned consists of the work done by researchers on branding in the insurance space for the existing consumers and potential consumers. Definitions of branding have diverged in recent years. Philip Kotler's (1991: 442) definition arguably remains the most commonly cited and meaningful for brand focused studies. According to Kotler, a brand can be defined as 'a name, term, sign, symbol, design, or combination of them which is intended to identify the goods and services of one seller or group of sellers and to differentiate them from those of competitors'. Both Aaker (1991) and Keller (1993) use the term brand association to group together anything either functionally or emotionally linked to the brand. Low and Lamb (2000: 351) suggest that marketers use such brand associations to 'differentiate, position, and extend brands, to create positive attitudes and feelings towards brands, and to suggest attributes or benefits of purchasing or using a specific brand'.

Adolescence is recognised as a time of fundamental change (Backett and Davison, 1995). Young people pass through a number of life-defining transitions; from family to peer group and wider society, from parental control to self-control and from dependence to independence. During this transition, identities are formed as beliefs and values become shaped by their surrounding youth culture and context. In this dynamic yet malleable environment, Eadie et al. (1999: 105) argue that 'conspicuous brands can perform a vital social function for young people seeking the acceptance of peers whilst still retaining the capacity to express their individualism and personal tastes'. Goodlad et al. (1996) go further, arguing that brands provide the means to minimise the risks of incorrect purchase choices, thereby providing insurance against possible peer rejection. Familiarity and acceptability therefore play important roles for young consumers seeking peer approval. Commercial brands traditionally achieve their 'youth credibility' as a result of the carefully crafted, symbiotic practices of awareness generation and image formation (Spero and Stone, 2004).

Brand awareness concerns the strength of the brand node or trace in memory (Keller, 1993) and concerns how well consumers can identify that brand under variable situations (Rossiter and Percy, 1987). In particular, it refers to how likely and how easily that brand name comes to mind, either prior to purchase or at the point of purchase. The former is traditionally known as brand recognition, the latter as brand recall. Brand awareness remains an important criterion for understanding how brands work as higher levels of awareness allow brands to become part of what is known as the consumer's 'consideration set' (Nedungadi, 1990).

Branding in financial services is undergoing substantial changes, owing to the dramatic increase in competition following deregulation (Denby-Jones, 1995; Jones, 1999) and the threat posed by new entrants with retail branding experience (Watters and Wright, 1994; Cleaver, 1999). Success in what is fast becoming an overcrowded market will depend on effective brand differentiation, based on the identification, internalisation and communication of unique brand values that are both pertinent to and desired by consumers. Financial services brands have, historically, exhibited little brand differentiation (Watters and Wright, 1994; Jones, 1999) and have been considered almost a commodity (Free, 1996).

\section{Objectives}

The overall objective is to study the attitude of consumers towards life insurance companies amongst the college students of Delhi and Mumbai. The specific objectives are as follows:

- Identification of consumers having a life insurance policy

- Evaluating the awareness levels of consumers towards life insurance

- Identification of life insurance companies with highest brand recall

- Identification of the most preferred brands in the life insurance space

- Identification of factors leading to a higher brand recall

\subsection{Primary sources}

\section{Research Methodology}

This study focuses on primary data collected through questionnaire. A primary survey has been conducted to identify the attitude of consumers towards life insurance in India. The survey was conducted in Delhi and Mumbai between Aug 2015 till Nov 2015. 


\subsection{Research Questions}

Research questions have been determined after reviewing contexts of consumer demographics and market set-up. In the process of setting the research questions the prospective future contribution of this research work also has been considered. The research questions aims to understand the attitude of selected respondents in terms of awareness, brand recall and brand preference.

\subsection{Research Design:}

This study has utilized survey research methodology. A highly structured questionnaire was developed based on discussions with selected university faculty, working professionals and literature review. The survey was circulated to students mails as well as in person. The population for this study are college students from Delhi and Mumbai. College students (Both males and females) are currently pursuing their graduation or post graduation from Delhi and Mumbai. The students are in the age group from 17 yrs to 24 years. A total of 810 respondents from the population have been selected. The selected sample size is further bifurcated into two categories based on the location. Students from Delhi constitute to $49 \%$ and from Mumbai, constituting remaining $51 \%$.

\subsection{Instrument Development:}

A two page questionnaire consisting of two subscales was developed. In the first subscale, general information pertaining to the respondents like sex, education level, geography and age were mentioned. In the second subscale, questionnaire focusing on consumer attitude towards life insurance have been taken into consideration. The consumer attitude fundamentally, covers the awareness level among consumers towards life insurance, brand recall of multiple life insurance companies in India, Most preferred brand amongst the insurers in the life insurance space and likelihood of purchase of a life insurance policy from insurers in the Indian market.

\subsection{Sample Profile:}

\section{Data Analysis}

The population of the study comprises of college students from Delhi and Mumbai, who are currently pursuing graduate or post graduate degrees have been included in the study.

\section{Exceptions:}

College students in school or with doctorate degree have not been taken into consideration.

A detailed breakup of the demographic variable is mentioned in the table below.

\begin{tabular}{|l|l|c|c|}
\hline Demographic Variables & Categories & No. Of Respondents (N) & Percentage \\
\hline \multirow{2}{*}{ Gender } & Male & 399 & $49 \%$ \\
\cline { 2 - 4 } & Female & 411 & $51 \%$ \\
\hline \multirow{2}{*}{ Region } & Delhi & 400 & $49 \%$ \\
\cline { 2 - 4 } & Mumbai & 410 & $51 \%$ \\
\hline \multirow{2}{*}{ Age (In years) } & $17-20$ & 393 & $49 \%$ \\
\cline { 2 - 4 } & $21-24$ & 417 & $81 \%$ \\
\hline \multirow{2}{*}{ Qualification } & Undergraduates & 659 & $19 \%$ \\
\cline { 2 - 4 } & Post Graduates & 151 & $81 \%$ \\
\hline
\end{tabular}

Table 1: Demographic Variables

Basis the questionnaire, multiple insights are derived for the selected population and are explained in the subsequent section. The insights are derived and compared for two separate geographic locations (1) Delhi and (2) Mumbai 
Distribution of respondents having a life insurance policy

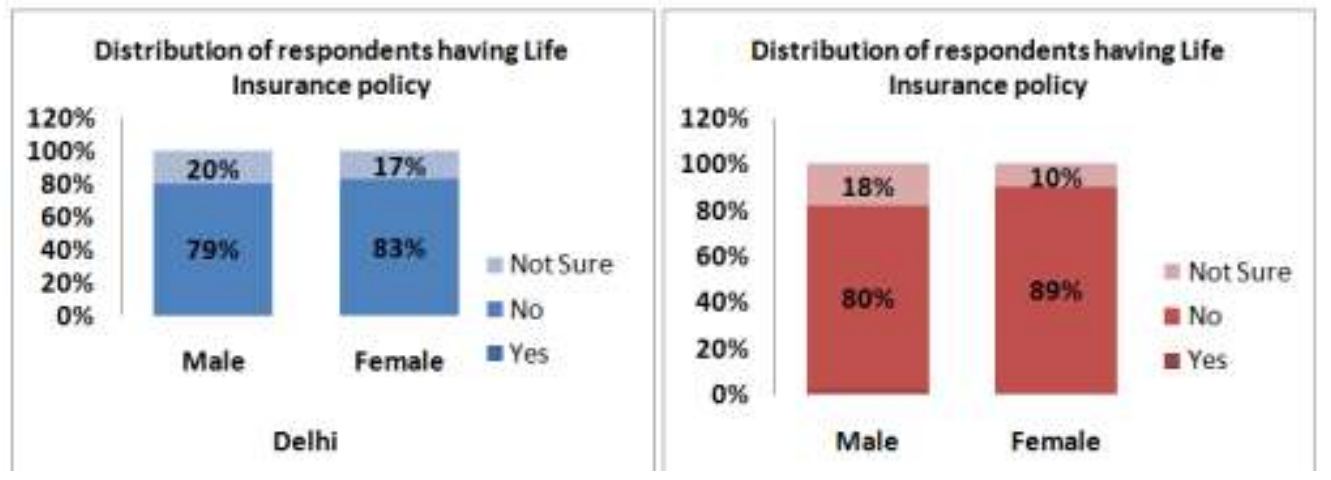

Figure 1: Distribution of respondents having a life insurance policy

It is seen that only $\mathbf{0 . 7 5 \%}$ from Delhi and $1 \%$ students from Mumbai have a life insurance policy that they are aware of. Majority of students either do not have a life insurance policy or are not aware, whether they have any insurance policy on their names. Of those having a life insurance policy, are post graduates and in the age group of 21-25.

\section{Awareness - Life Insurance}

On being asked about the awareness levels towards life insurance, they were very low across college students of Mumbai and Delhi. Around 2.5\% of students from Delhi and Mumbai are familiar with the concept of life insurance and its advantage whereas around $97 \%$ of students are either slightly familiar or not familiar at all with the concept of life insurance. Familiarity pertaining to life insurance is more in post graduate students as compared to graduates across Delhi and Mumbai.

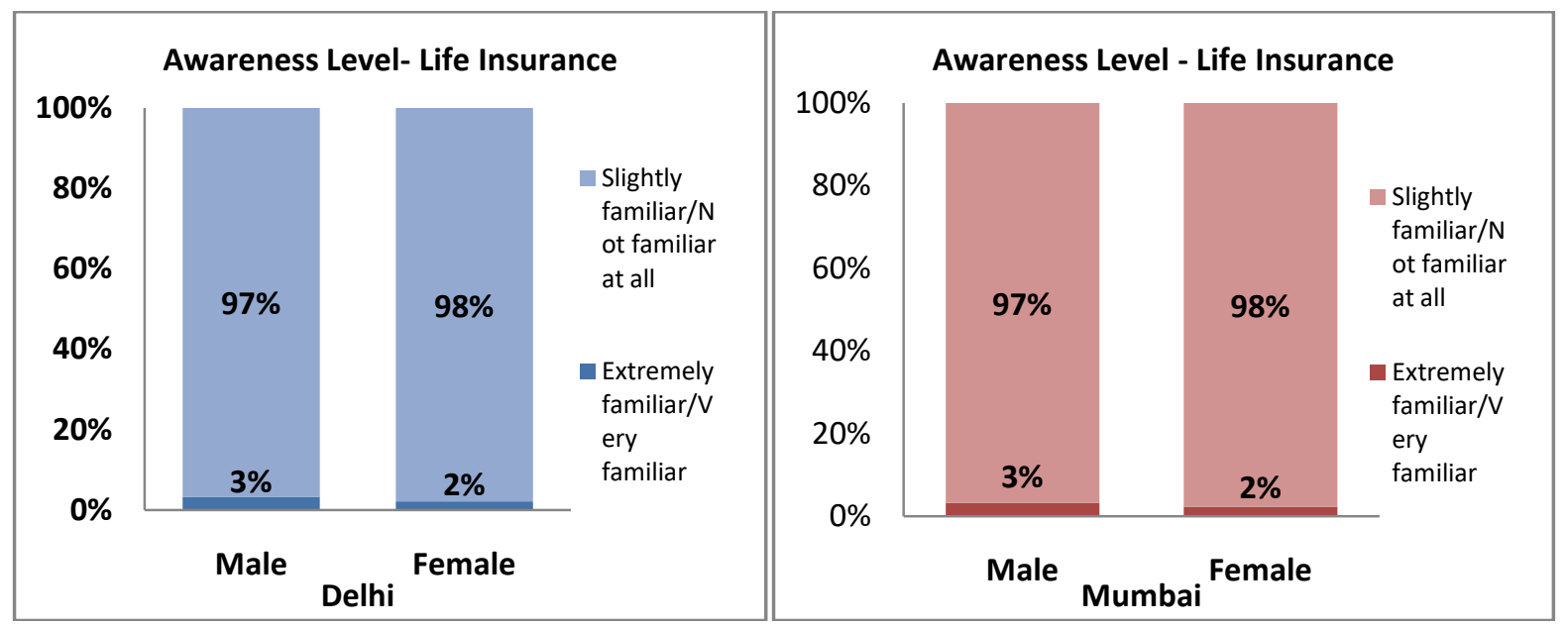

Figure 2: Awareness - Life Insurance

Brand recall - Life Insurance Companies

When the respondents were asked to recall brands from the life insurance space they know of, the top four brands which they were able to recall are mentioned in the image below.

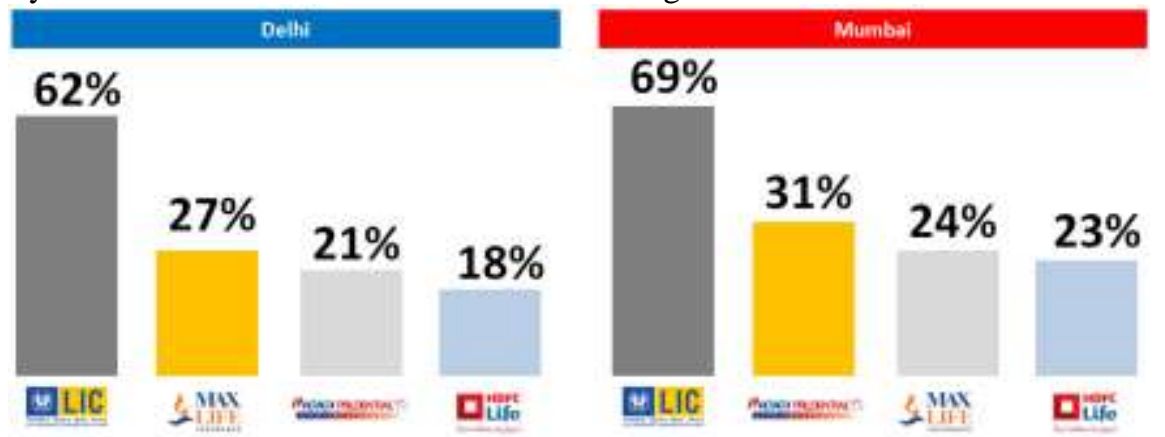


Figure 3: Brand recall of life insurance companies

LIC across Delhi and Mumbai has the highest brand recall followed by Max Life, ICICI Prudential and HDFC Life. It was noticed that the main reason behind LIC being at the forefront was due to the fact that it was more prominent among their respective parents and someone in the family was insured with LIC. Whereas for Max Life, HDFC Life and ICICI Prudential, it was either there advertisements on TV or discussion among peer groups. TV commercials of HDFC Life on "Sar Utha Ke Jio", "Bande Acche Hai" in case of ICICI Prudential and "Aapke Sacheche Advisor" in case of Max Life were the main reason for the recall. The students felt that these commercials create positive feeling about the brands and hence were on top of their minds in case of brand recall.

\section{Brand Awareness - Life Insurance Companies}

A list of life insurance companies were provided to the respondents and they were asked to select those that they are aware of. The top nine life insurance companies basis the respondent selection is provided below. Interesting point to note is that most of the life insurance companies identified by the respondents are those which have a joint venture with a brand known to the respondents. For example, HDFC bank in case of HDFC Life, ICICI bank in case of ICICI Prudential and Birla group in case of Birla Sun Life. Awareness levels among post graduates were higher as compared to graduates across Delhi and Mumbai. Also, males across both the cities were aware of more life insurance companies as compared to their female counterpart. One of the reasons for higher brand recall and brand awareness can be attributed to the fact that many of the companies higher students at a management trainee level from multiple B schools in Delhi and Mumbai.

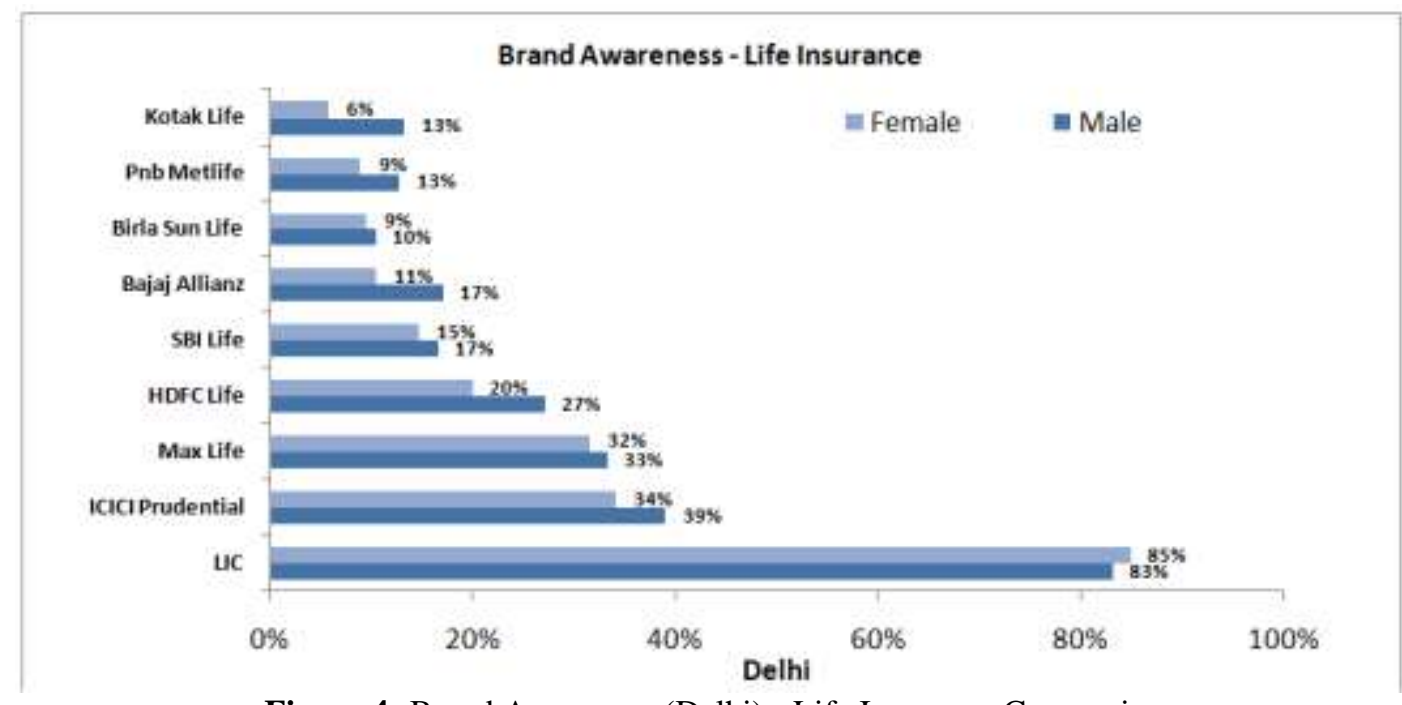

Figure 4: Brand Awareness (Delhi) - Life Insurance Companies

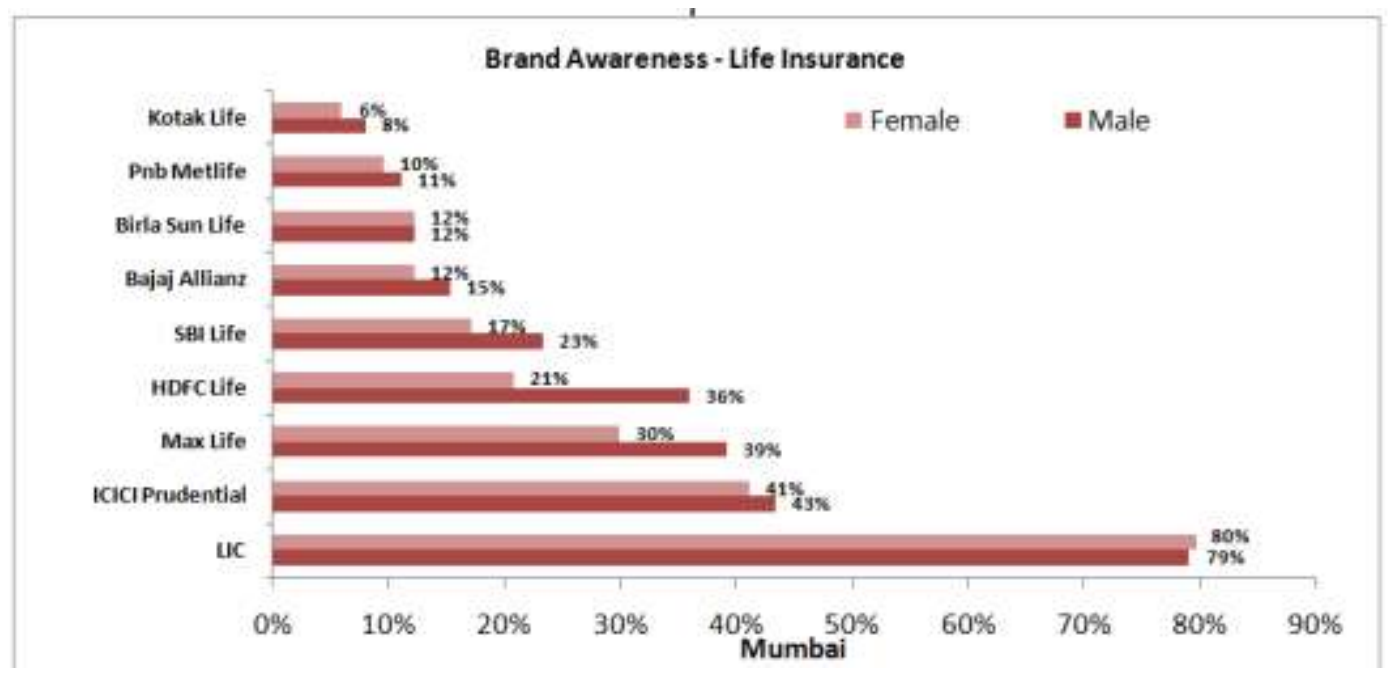

Figure 5: Brand Awareness (Mumbai) - Life Insurance Companies 


\section{Most preferred insurer}

The respondents were asked to choose the two most preferred life insurance companies with which they would like to get insured with and the results are shown in Fig. 6 and 7. The most preferred life insurance company was LIC followed by ICICI Prudential.

The top three reasons basis which the respondents made their choices were:

1. Their parents are insured with the respective insurer (41\%)

2. They have seen advertisements on TV and Internet, and feel more connected with them as compared to any other brand. (27\%)

3. These brands are most talked about within the peer groups (19\%)

LIC is the most preferred brand across Delhi and Mumbai whereas Max Life is the preferred choice in Delhi and ICICI Prudential is the preferred choice in Mumbai.

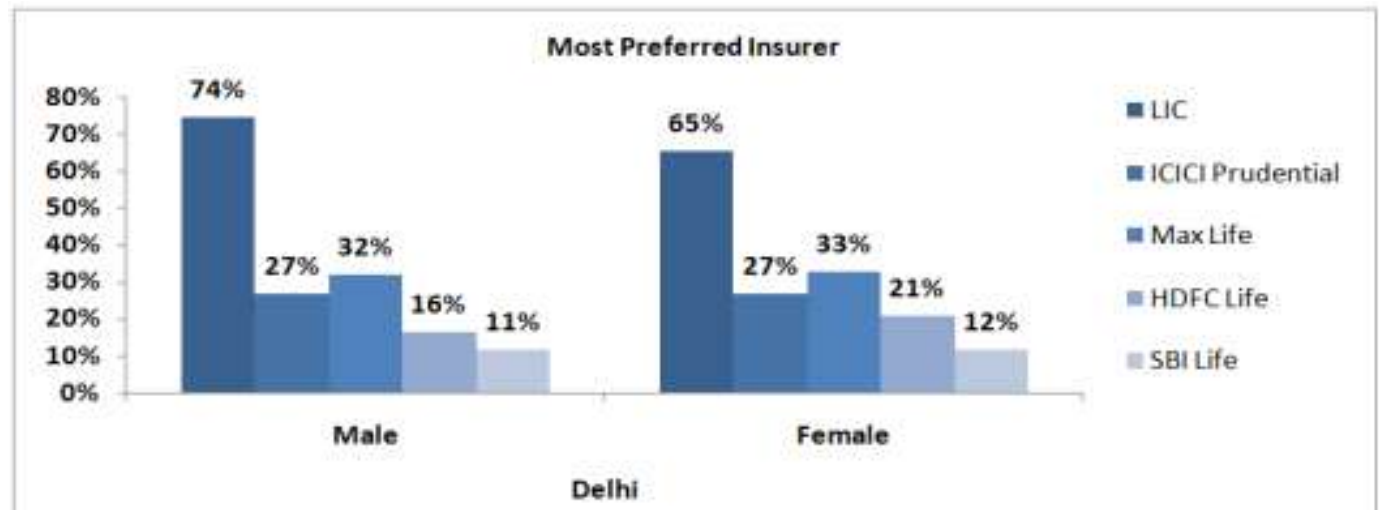

Figure 6: Most preferred insurer (Delhi)

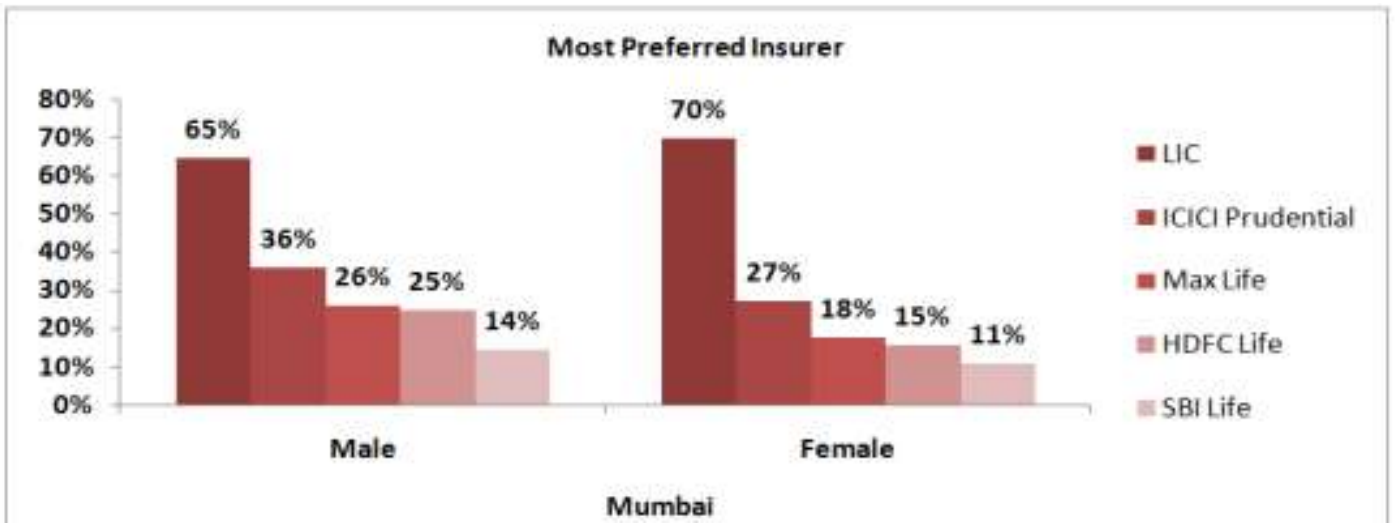

Figure 7: Most preferred insurer (Mumbai)

\section{Do you feel the need to buy life insurance at an early stage}

The respondents were asked about getting insured at an early stage and the figure below represents their state of mind. Students from Mumbai have a more positive outlook as compared to Delhi. Students pursuing their post graduation across Delhi and Mumbai feels that getting insured at an early stage is better. Also, males across Delhi and Mumbai feels that it is important to get insured at an early stage. Considerable amount of students feel that they are not aware whether they require life insurance at this stage and would explore the option at a later stage.
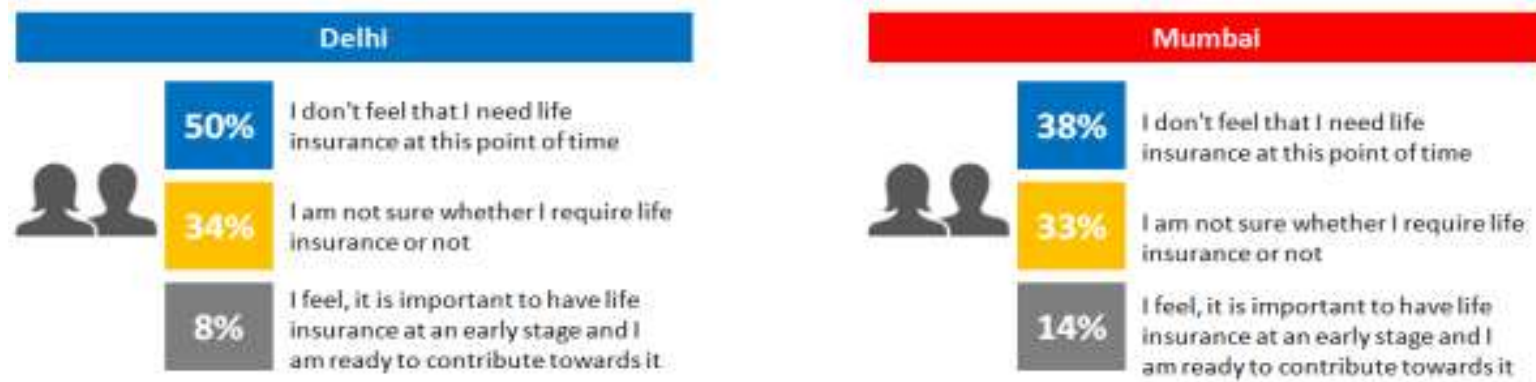
Figure 8: Need to buy a life insurance

\section{Conclusion and Practical Applications}

Key findings from the study:

- Student awareness pertaining to life insurance is extremely low across Delhi and Mumbai

- Awareness levels among post graduate students is higher as compared to graduates across Delhi and Mumbai

- Life insurance companies with a higher brand recall is attributed to specific TV commercials and peer groups

- Higher brand recognition or recall is attributed to the brands associated with name of life insurance companies. For e.g. HDFC bank in case of HDFC Life etc

- $\quad$ LIC is the most preferred life insurance company across the two cities followed by Max Life in Delhi and ICICI Prudential in Mumbai

- Higher brand preference is attributed to family members or relatives insured with a specific brand and commercials shown over TV or internet

- Students in Mumbai have a positive outlook towards life insurance as compared to Delhi

Insurance is a push based product so aggressive selling might not be the only way to achieve a robust growth for life insurance companies. It is essential that the consumer believe that brand is important while purchasing a life insurance and in order to do that, companies need to come up with initiatives to create awareness among college students and develop a connect with them. Creating awareness among college students would lead to potential consumers for future. The life insurers can gauge what has worked for them till date as far as branding is concerned in terms of TV commercials, brand ambassadors and advertisements. The study will also help them in evaluating the attributes that are important for consumers as far as a branding is concerned. Customers' predispositions toward brands are particularly important because, as a prerequisite, brands need to be relevant to the customer to hold any economic relevance for the firm. Life insurance companies need to create such a brand that if not purchased, it at least is talked about among the masses, with a positive context. By doing so, companies would give rise to a set of consumer, creating a positive brand image among other masses. Strategic partnership with colleges and e-commerce players is vital in order to create an ecosystem favourable to all the entities involved. Partnering with colleges and doing competency building, delivering guest lectures and management training programs can help companies in creating awareness among college students. Partnering with e-commerce companies can be done in order to create co branded programs between life insurers and e-commerce companies.

\section{Future Research}

This research focuses on college from Delhi and Mumbai only. If the scope of the research is expanded to other cities in India and include students of other education levels, a holistic view of the consumer preference and behaviour could be gauged. Secondly, the attributes which results in higher brand recall or preference can also be studies in depth in order to assist companies in having a targeted branding strategy in place. The subsequent part of this study is identification of potential partnerships with e-commerce companies and colleges in India along with the set of strategic initiatives, life insurance companies can take in order to create a stronger brand presence and promise in the minds of existing and potential consumers.

\section{References}

[1]. Aaker, David A.(1991), Managing Brand Equity: Capitalizing on the Value of a Brand Name . New York : The Free Press.

[2]. Arnold, P., B. Wheeler, C. Abernathy, and R. Bates, 1999, Shopping for Value: Insurance Distribution in the Information Age, CPCU Journal, 52(3): 140-152.

[3]. Chaudhari, Arjun \& Holbrook, Moriis B (2003). The chain of effects from brand trust and brand affect ro brand performance : The role of brand loyalty, American marketing association

[4]. Cummins, J. David and Mary A. Weiss, 2000, "Analyzing firm performance in the insurance industry," in Georges Dionne, ed. Handbook of Insurance, Boston, MA: Kluwer Academic Publishers.

[5]. D. Tripati Rao.(2000). Privatisation and Foreign Participation in (Life) Insurance Sector: Economic and Political Weekly, Vol. 35, No. 13 (Mar. 25-31, 2000), pp. 1107-1120

[6]. Dubin, J. A. 1998. The demand for branded and unbranded prod- ucts: An econometric method for valuing intangible assets. Studies in Consumer Demand: Econometric Methods Applied to Market Data, Chapter 4. Kluwer Academic Publishers, Norwell, MA, 77-127.

[7]. Erdem, TuTin and Joffre S wait (1998), "Brand Equity as a Signal ing Phenomenon," Journal of Consumer Psychology, 7 (2), 13157.

[8]. Erdem, T., J. Swait, A. Valenzuela. 2006. Brands as signals: A cross- country validation study. /. Marketing 70(1) 34-49.

[9]. Fombrun, C. J. (2005). The leadership challenge: Building resilient corporate reputations. In J. P. Doh \& S. A. Stumpf (Eds.), Handbook on responsible leadership and governance in global business (pp. 54-68). Cheltenham: Edward Elgar.

[10]. Gardner, Lisa A. and Martin F. Grace, 1993, "X-efficiency in the US life insurance industry," Journal of Banking and Finance, Vol. 17, No. 2-3, pp. 479-510. 
[11]. Kapferer, Jean-No?1 (2008), The New Strategic Brand Management: Creating and Sustaining Brand Equity Long Term, 4th ed. London: Kogan Page.

[12]. Keller, K. L., D. R. Lehmann. 2006. Brands and branding: Research findings and future priorities. Marketing Sci. 25(6) 740-759.

[13]. Spero I, Stone M. 2004. Agents of change: how young consumers are changing the world of marketing. Qualitative Market Research: An International Journal 7(2): 153-159

[14]. Srinivasan, V., C. S. Park, D. R. Chang. 2005. An approach to the measurement, analysis, and prediction of brand equity and its sources. Management Sci. 51(9) 1433-1448.

[15]. Thorsten Beck and Ian Webb. (2003). Economic, Demographic, and Institutional Determinants of Life Insurance Consumption across Countries: The World Bank Economic Review, Vol. 17, No. 1 (2003), pp. 51-88

[16]. Wolfe, L. (2013). Branding strategies targeted towards kids: When food talks, kids listen—And parents buy. Women in Business/About.com. Retrieved November 27, 2013 